\title{
Miranda
}

Revue pluridisciplinaire du monde anglophone /

Multidisciplinary peer-reviewed journal on the English-

speaking world

$12 \mid 2016$

Mapping gender. Old images ; new figures

\section{AS - Situating Change: Combinatory Writing, Interdisciplinary Collaboration, Technology, and Political Reality}

\section{Scott Rettberg}

\section{OpenEdition}

\section{Journals}

Electronic version

URL: http://journals.openedition.org/miranda/8751

DOI: $10.4000 /$ miranda.8751

ISSN: 2108-6559

\section{Publisher}

Université Toulouse - Jean Jaurès

\section{Electronic reference}

Scott Rettberg, "AS - Situating Change: Combinatory Writing, Interdisciplinary Collaboration, Technology, and Political Reality", Miranda [Online], 12 | 2016, Online since 01 March 2016, connection on 16 February 2021. URL: http://journals.openedition.org/miranda/8751 ; DOI: https://doi.org/ $10.4000 /$ miranda. 8751

This text was automatically generated on 16 February 2021.

\section{cc)}

Miranda is licensed under a Creative Commons Attribution-NonCommercial-NoDerivatives 4.0

International License. 


\section{AS - Situating Change: Combinatory Writing, Interdisciplinary \\ Collaboration, Technology, and Political Reality ${ }^{1}$}

Scott Rettberg 


\section{Tokyo Garage and Creative Cannibalism Illustration \# 1}

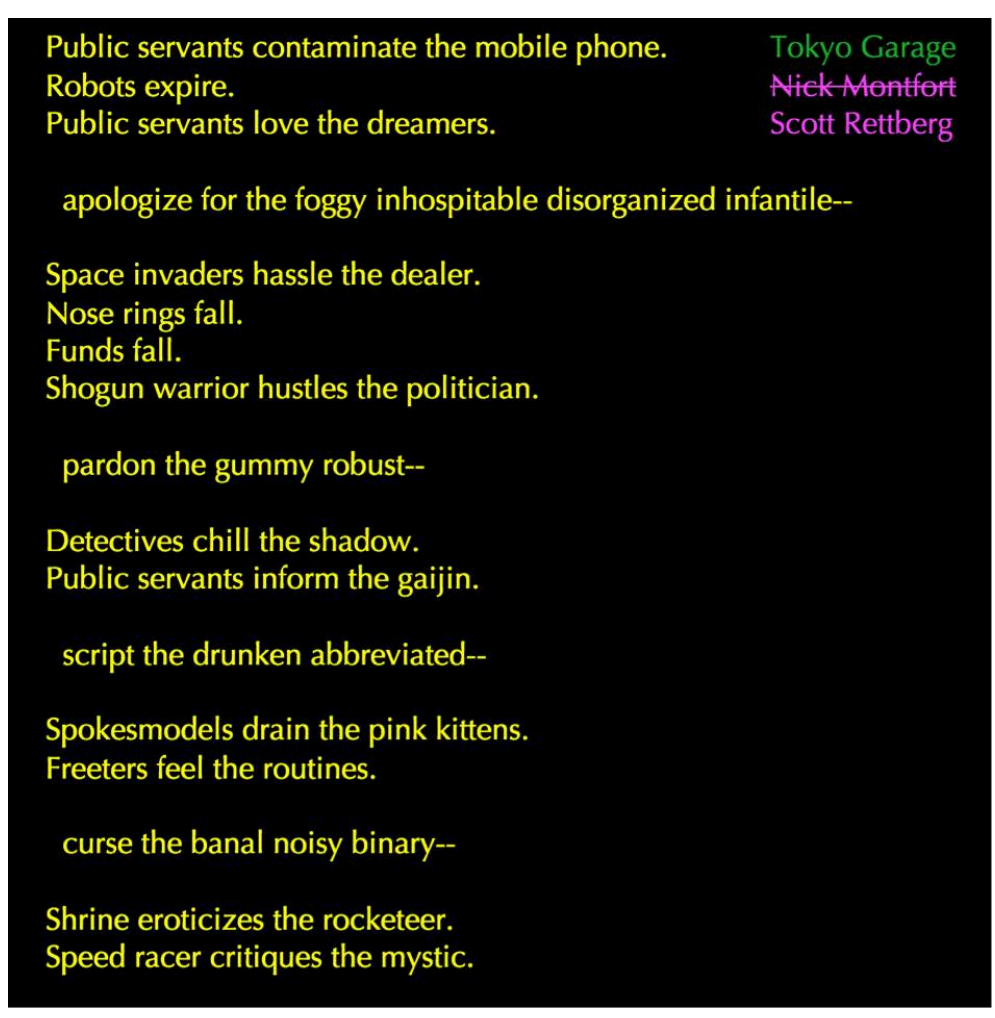

Screenshot from Tokyo Garage by Scott Rettberg.

1 Tokyo Garage, might seem to be apolitical or perhaps even absurd, but it reflects a kind of aesthetic politics that I would like to explore, a mode of practice built on sharing, on collective building, on dialectics, and on a sense of play.

2 The network is not an anarchic environment. At this point we would be hard-pressed to even think of it as a democratic space. I am old enough to remember a time when it was perceived otherwise. I remember my first encounters with the fascinations of the network-my sense of wonder that one could for instance use Fetch to download files via ftp, say photographs of Egyptian monuments, that had been uploaded half of a world away. I remember my joy at encountering Project Gutenberg the first time-the idea that volunteers all over the world were scanning, typing in texts, the world's great works of literature, as well as forgotten texts that had been allowed to go out of print or gather dust in isolation. The week in 1993 that the first World Wide Web browser, Mosaic, came out, I was taking an MA class at Illinois State University called Visual Rhetoric, and I remember that Jim Kalmbach, my professor, cancelled most of whatever we had scheduled for that day to show us the browser that the National Supercomputing Agency at the University of Illinois had just released to the general public. We had been using email and FTP for years, but this was truly different. Using a simple easy-to-learn markup language, people all over the world were not only able to share files, texts, images, sounds, and even video, but to bring all of these media elements together in one universally accessible multimedia environment. We could see, and shape, and design in this new space, and by simply publishing materials on a server, we could make them instantaneously available to anyone with an Internet 
connection. We could each, he encouraged, stake a claim here, set up a "home page" and join in a publishing revolution. Every writer could be a publisher here, every digital artist could have a gallery. And the mind reeled at the possibilities. We could conceptualize new art forms, we could imagine new kinds of social and political engagement, we could dream up consensual communities that transcended borders and governments. Walls had fallen everywhere, and for a moment it seemed as if the World Wide Web represented a technological manifestation of possibility, a potentially worldchanging thing.

In retrospect, I suppose that we now remember this techo-utopianism in the same way that the radicals of the 1960s remember the protest movements of their youth, long before they got their corporate jobs, mortgages, and sports utility vehicles. The network has largely become a network of capital exchange dominated by a relatively small group of corporate actors, information-and-attention brokers who supply us with great bread-and-circus: an inexhaustible ocean of data, the greatest library the world has ever known, nearly-simultaneous one-click delivery of goods and services, three dimensional printed artifacts and books-on-demand, any song you can think of, detailed updates on the everyday lives of our friends, companionship, debate, tweets from near and far, the best one-liners from thousands of academic conferences-all taking place at the same time, sweet whispers from our lovers, taunts from our terrorists, photos of our children at play, messages from a rover on Mars and a Rosetta lander as it drifts to sleep on a stone hurtling through the galaxy.

4 This network provides us with many wonders, this World Wide Web, and yet it is somehow a smaller place than it once seemed it might have become. I go to the same few sites over and over again. I use the same few platforms over and over again. I am writing these words on a Google doc that lives a fictional cloud that is really a connection to my packets made into bits on a server farm in an unknown location, a server farm that is part of a network of server farms distributed around the world and consuming enormous amounts of energy every millisecond. I am writing to this network and entrusting this writing to this corporate actor. If I spill my glass of water on this computer made by another corporate actor that I also entrust with a good deal of my information, my art, and my human relations, the writing will not go away even as my motherboard sizzles and pops, for the writing will live on in these server farms we call the clouds. And now I am pasting these words to another server farm. I am one of the animals that lives on these server farms in the clouds. I am one of the animals who grazes in these server farms, who looks up into these clouds. I have a pretty good life on this server farm, I can move from this server farm to another server farm, my masters are not jealous masters, they spare me the brand though they have collared me. They allow me to wander from server farm to server farm, wearing my bells. My friends live on these farms as well, and we do not have it so bad, we are well fed here on these farms, and we can see each other and we can hear each other's bells and we can share with each other, know each other, and like each other, on these farms. We can write each other on these farms. And yet, and yet, and yet it is not a cloud here, it is not my cloud here. It is a metaphor here, and it is a not a metaphor that I own here. It is not even a metaphor that I like here. It is a farm here, and I am an animal on that farm, and all my friends are animals on that farm. We like to think of it as our farm, but somebody else owns our farm. Somebody with no body owns this server farm. Some 
they owns the farm. They are unknowable and they are legion. They are an it. Long ago it invited us onto the farm, and we bought the farm, and we like (it) here.

5 Farm animals are, of course, eventually brought to the abattoir and turned into sausages and hamburgers. Our social networks and international megamalls and search engines and mapping sites and personal surveillance networks and extrinsic memory hordes treat us better than that, of course. We are only rarely brought to slaughter, but we are continuously harvested nevertheless. Our language is bought and sold and used to train intelligent machines, our locations are known and triangulated with our search history, our demographics are scrutinized, our friends are used to increase market affinities. Our entertainment, our research, our social relations, our purchases, our correspondence, our explorations, our soothing, our condolences, our congratulations, our lives online are transformed by intelligent algorithms into labor. The most significant story of the contemporary Web is the story of human computation ${ }^{2}$, the story of processes that harness the everyday activity of internet users in computational activities that yield massive capital returns for the corporations that harvest them.

The contemporary Web is no longer a constellation of quirky home pages and projects built by small groups in their spare time. The network is now mostly a landscape of corporate farms, and most of us live on these corporate farms most of the time. I would be a liar if I said that I do not like living here, or that I am really some kind of activist against life on the farm ${ }^{3}$. I am just as much a farm animal as most of my friends, maybe even more so. Life on the farm is fun. We roll around in the mud with our friends and we have access to incredible views. Yet if the phenomenological experience of the internet has changed, if we have moved from many channels to fewer channels with many voices, from a more individuated Web to one that steers us towards flocking and herding behaviors, if we are all serving multinational corporations, surveillance states, nefarious spam merchants, and other less-than-transparent human and non-human operators with our every post, every purchase, every click, every interaction, it is also the case that aspects of the other Web, the one that we corrupted techno-utopians still remember, remain available to us. Subnetworks of individual and collective creation that have little to do with capital and much to do with artistic creation, a gift economy, critical engagement, and social activism, still exist. And here is where something like an online poetry generator might be said to at least gesture towards a certain type of aesthetic politics.

7 Tokyo Garage is a rewriting, an overwriting, of Nick Montfort's nature poetry generator Taroko Gorge. Nick Montfort's program produces a meditative observation of a particular feature of a natural park in Taiwan. When I first saw Taroko Gorge, I admired the program's elegance, and the very irony of a text generation machine that results in a nature poetry. It is a sparse, minimalist program that, like many of Montfort's other works, expands from a small core of code to a lively and streaming poem that, like a waterfall, will continue to run and vary in subtle ways as long as you look at it. This type of poetry generator can be said to be first an act of compression, then a rewarding decompression at run time, with aleatory arrangements resulting from the algorithm. 


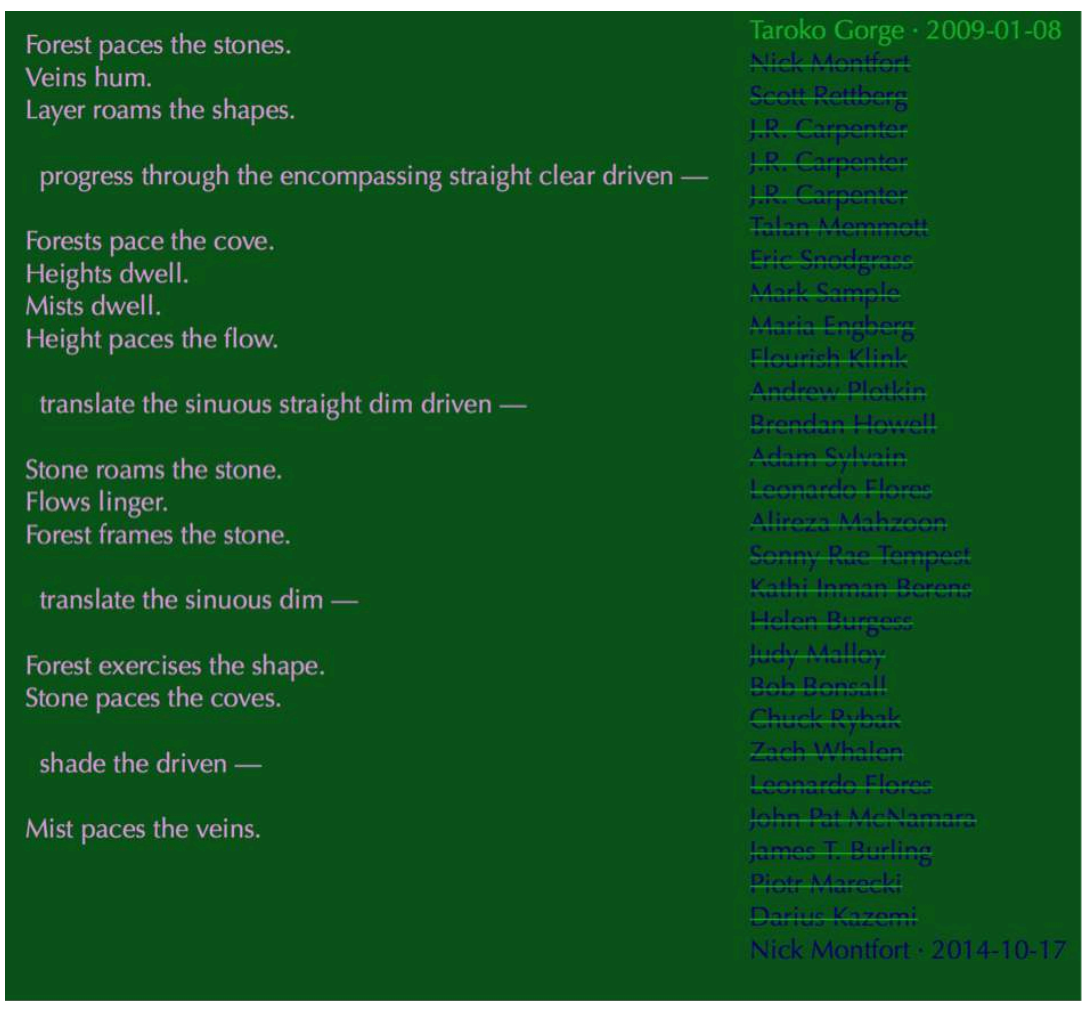

Screenshot from Taroko Gorge by Nick Montfort.

8 When Nick posted Taroko Gorge online in 2009 I decided to try my hand at hacking the engine, to see if I could invert and subvert it in a number of ways: to turn a poetry generator about nature into a generator about the cosmopolis, to take a minimalist work and turn it into to a maximalist work, to turn a light, almost zen work, into a noirish, and almost anarchic work. Working mainly with the vocabulary of the arrays, I changed all of the language while leaving the majority of the original code in place. I wrote a new poetry generator on Montfort's platform. I originally did this mostly as a kind of in-joke or constrained writing game, which I thought would amuse my friend and collaborator. I did this without Montfort's explicit approval. To ask permission would eliminate the surprise, and the nature of the work as a hack. I crossed out Montfort's name and put my own name beneath it on the author line, providing acknowledgment via strikethrough, and then posted the new generator online.

There is a political economy at work here: begin with the very fact of the poetry generator's existence on the open network. A poetry generator serves no market function whatsoever. It harvests nothing from its reader. In fact, it offers itself to you as a gift. I could appreciate Nick Montfort's poem, open its source code, devour it, digest it, and in what Chris Funkhouser has called an act of anthropophagy, use it as the source for something new derived from it and including many of its elements. While this act was unsanctioned, Montfort's response was not to loathe this act of cannibalistic plagiarism, but to celebrate it, to repost the new creation and to encourage others to join in and behave similarly. Soon thereafter came J.R. Carpenter's Gorge, a poetry generator about the eating body, Talan Memmott's Toy Garbage, about cheap toys and kitsch culture, Eric Snodgrass's Yoko Engorged, a smutty treatment of John Lennon and Yoko Ono in bed, Mark Sample's Takei, George, about the Star Trek 
actor, gay rights activist, and internet personality. Dozens of other variations have followed.

\section{Illustration \#3}

Nose stuffs the bladder.

Guts cool.

Morsels warm.

Jaw stimulates the taste buds.

note the burnt cassis cinnamon herbaceous -

Digestive tract nibbles the films.

Meals heat.

Mouths evaporate.

Thirsts strain the dip.

sip the blackstrap cardamom colourful -

Head stirs the tongues.

Incisor melts the finger tips.

inspect the berry cinnamon -

Brain chars the vinaigrettes.

Lower lips age.

Molar juliennes the thick spread.

study the burnt herbaceous liquorice -

\section{GORGE}

Nick Mentfort

J.R. Carpenter

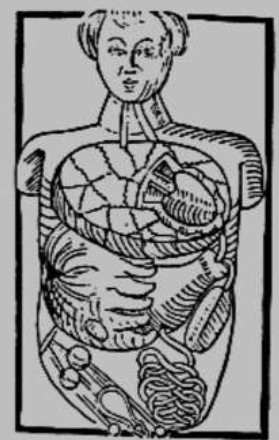

Screenshot from Gorge by J.R. Carpenter

\section{Illustration \#4}

Johns tease the lips.

Johns suck the nipples.

observe closely the cocky pleasing momentary trick nakedness --

Fat old mother hen puckers the pie.

Lennons cup the grapefruit.

frame the fetish striptease --

The generator sucks the hips.

The audience volunteers linger.

Johns exercise the fat old mother hens.

take a tape of the sound of the full-voiced untamed back row of the Soho movie house in and out --

The generator flogs the pie.

Intimate parts fuck.

Pies fuck.

Screenshot from Yoko Engorged by Eric Snodgrass.

What began with Montfort's gesture of sharing a poetry generator on the open web, followed by my gesture of hacking, re-posting, and sharing again, has become a kind of internet phenomenon of sharing and creative cannibalism. It has also, not inconsequentially, served as a kind of gateway drug for writers new to electronic
YOKO ENGORGED

ickMontfort

J.R. Carpenter Falan Memmott Eric Snodgrass 
literature. Taroko Gorge supplies a route around the barriers to entry to digital writing for poets who might be interested in digital forms but are intimidated by programming. Whenever I'm talking with another writer interested in e-lit but who says "I'd love to try something like that but I don't know how to code," I open up the source of Taroko Gorge and say "Ah, perhaps you can't code yet, but surely you can replace some words with other words and see what happens?" Digging a new Gorge is that simple, yet it opens up strange and compelling complexities. Indeed Taroko Gorge is now often used as a teaching tool in electronic literature classes. Students in Kathi Inman Berens's Electronic Literature course at the University of Bergen, for example, have produced twenty new Gorge-based generators this semester alone, each radically different from the other, and in the process learned some essential lessons about digital writing, computation, web design, and the alternative social network that electronic literature comprises.

11 In his writings on technologies of memory, Bernard Stiegler distinguishes between technologies that exteriorize memory in differing ways. Anamnetic technologies of memory, such as writing, require both the sender and the receiver be able to both code and decode them. Anyone who can read can also write. Stiegler distinguishes between these anamnetic technologies and industrial hypomnemata-such as Hollywood films for example-which separate producer from consumer. There is then a loss of individuation in industrial hypomnemata. The viewer becomes part of a mass audience unable to respond in the same form. I can consume a Hollywood film but I cannot easily produce one in response. Stiegler finds the potential for anamnesis in digital technologies as he writes, "Cooperative digital technologies can be placed in the service of individuation, but only if the industrial politics of hypomnesis are implemented in the service of a new age of anamnesis." (Stiegler 84) The Taroko Gorge / Tokyo Garage phenomena is an example of true digital anamnesis. While I can write and respond to friends on Facebook, I cannot harvest and cannibalize from Facebook in the same way that is harvesting and cannibalizing from me. But I can cannibalize Taroko Gorge, and you can cannibalize Tokyo Garage, and we can go on sharing and cannibalizing and building on and recycling each other's work until the cows come home, in a reciprocal, anamnetic relation. This farm is our farm.

\section{Implementation: Writing on the World}

I will next read from an earlier work, also produced in collaboration with Nick Montfort, the sticker novel Implementation. 


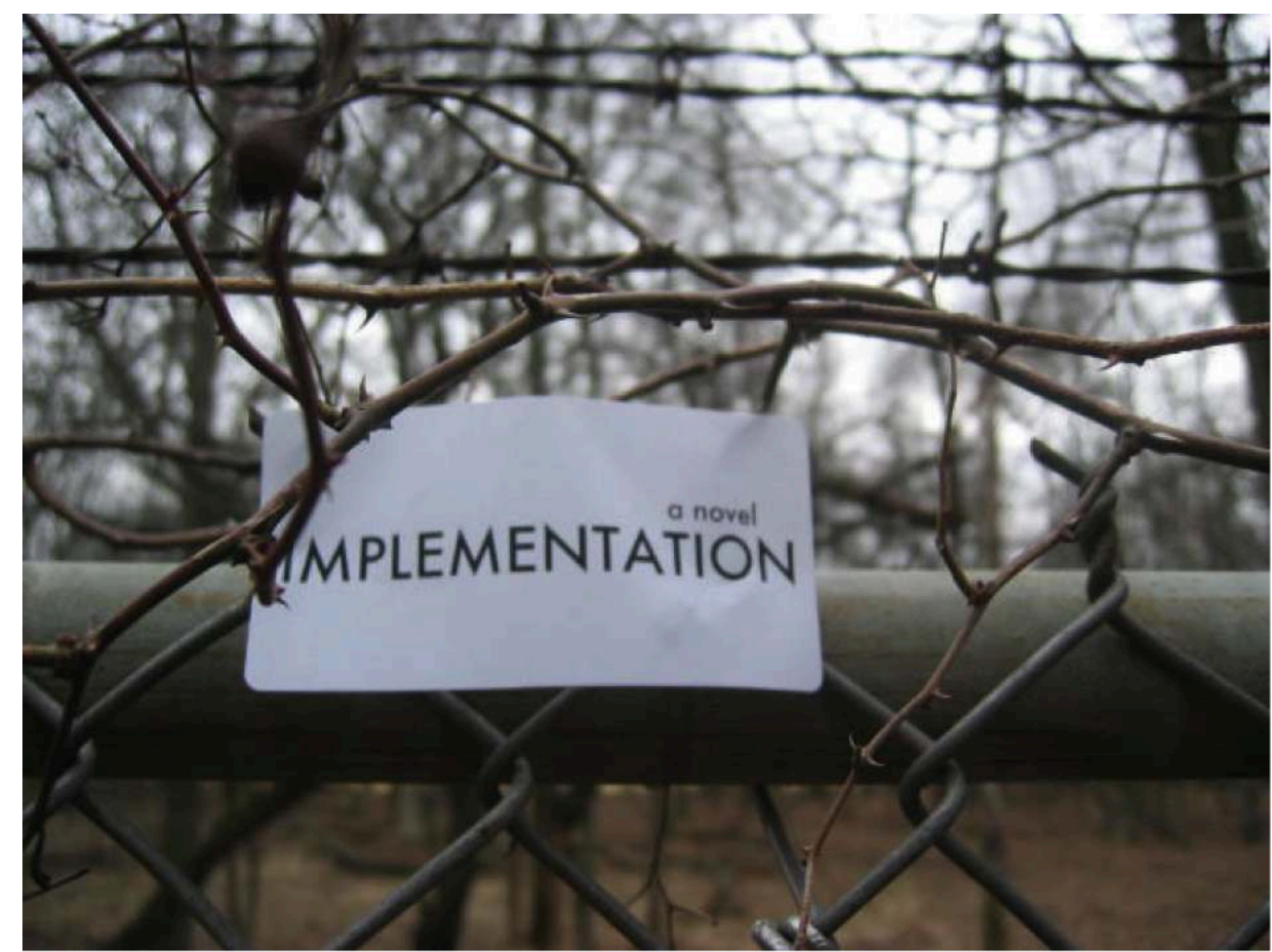

Photo of title sticker from Implementation on fence of elk enclosure in Elk Grove Village, Illinois.

13 Implementation is a novel about psychological warfare, American imperialism, sex, terror, identity, and the idea of place, a project that borrows from the traditions of net.art, mail art, sticker art, conceptual art, Situationism, serial fiction, and guerrilla viral marketing. Implementation was first published in 2004-2005 as a serial novel made of 240 stickers, which were distributed in 8 installments of 30 stickers each. Readers then posted the stickers in public spaces around the world, photographed them, and returned those photographs to the project site, where they are archived by date and by location. In 2009-2010, the project was "re-implemented"-sent out to new participants, who installed the fragments of the novel in more locations, in order to gather new photos for a book project, which was published in 2012. The project has also been situated in the Web 2.0 context, as we have uploaded the photo archive to Flickr, and categorized and semantically tagged the images in the archive.

Implementation is about four people who live in a Midwestern American town named "Implementation." The action of the novel begins in September 2001 and runs through the beginning of Operation Iraqi Freedom in 2003. One of the characters, Kilroy, is a reservist who is called up and then sent to Iraq, but the others-Frank, CEO of a cardboard box manufacturer; Samantha, Kinko's employee; and Roxanne, who develops desktop publishing software-are affected in much more oblique ways by the attack on the World Trade Center and the United States' global war on terrorism. They continue to dine at restaurants, drink at bars, work, worry about their jobs and careers, notice what new stores are opening up, have flings and relationships, and go to celebrations and funerals. Even a bombing in town changes little on the surface of their lives. At the same time, the war's inception and progress can be read in the shifts in their gestures, longings, and language, as the peripheral, everyday psychological tolls of the "war on 
terror" become evident. Implementation is a historical novel about a time in America that seems too recent to analyze, but whose important subtleties have already been largely repressed or forgotten.

Illustration \#6
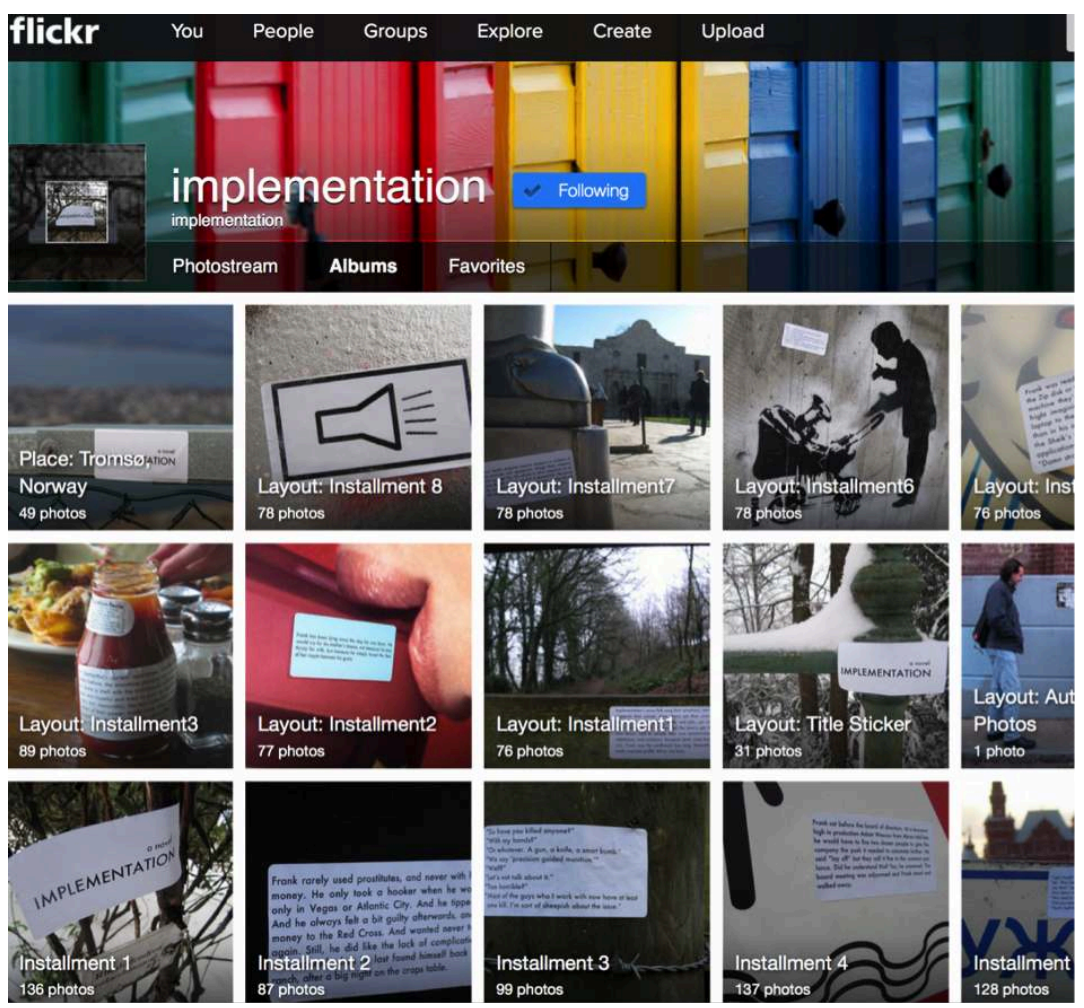

SCREENSHOT OF IMPLEMENTATION PHOTO ARCHIVE ON FLICKR, WHICH NOW INCLUDES 3,486 PHOTOS.

A few elements that I think particularly important to emphasize about Implementation include:

1. The text was attempting to respond to particular changes in the lived environment that Nick and I perceived as oppressive: the atmosphere of continual fear and the rise of a ubiquitoussurveillance "security state" after $9 / 11$, accompanied by a politics of perpetual war. So the form of the novel, in stickers that would adhere to public surfaces of the world, was in response to the intrusive nature of many other texts, and laws and practices of paranoia and surveillance, which became prevalent after 9/11. 


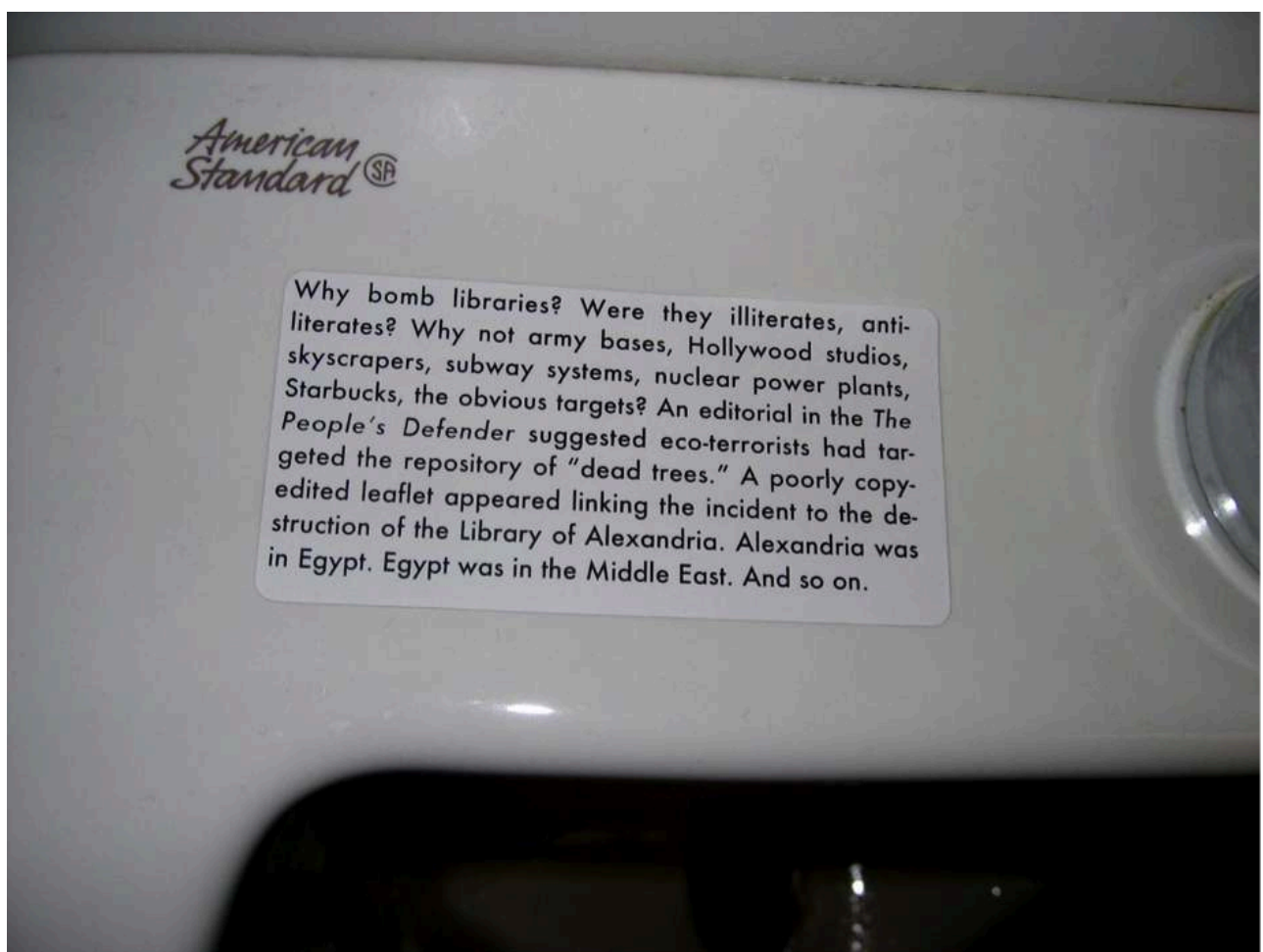

Implementation sticker on a urinal in a public restroom at the RISD Museum in Providence, Rhode Island.

1. We can identify a number of different categories of readers of Implementation, each of whom experienced the project in a phenomenologically different way, even as a different artifact, based on the context in which they encounter it. The groups of "readers" of the project include the initial subscribers, who read the novel in its entirety in 8 separate installments received over the course of a year, 30 texts at a time, participant readers who chose to place the stickers in the physical world and photograph them, online readers who either read the PDF files online, or browse through the archives of photographs, readers who encounter the project at random in the physical world, art gallery readers, who have encountered images of Implementation in museum or gallery contexts, and finally book readers, who will encounter documentation of the novel in its entirety as a photo book. The "participant" readers of Implementation were, importantly, asked to do something marginally subversive, and in some contexts illegal. Although business-sized shipping label stickers filled with narrative text are hardly most conspicuous form of graffiti, and they are easy to remove, putting up, photographing, and leaving behind a text is performative in a different way than simply reading it. These participants were also interpreting the text and translating it into a new form, a photograph of a text in space, and so became co-creators of the work in a very material way. 
Illustration \#8

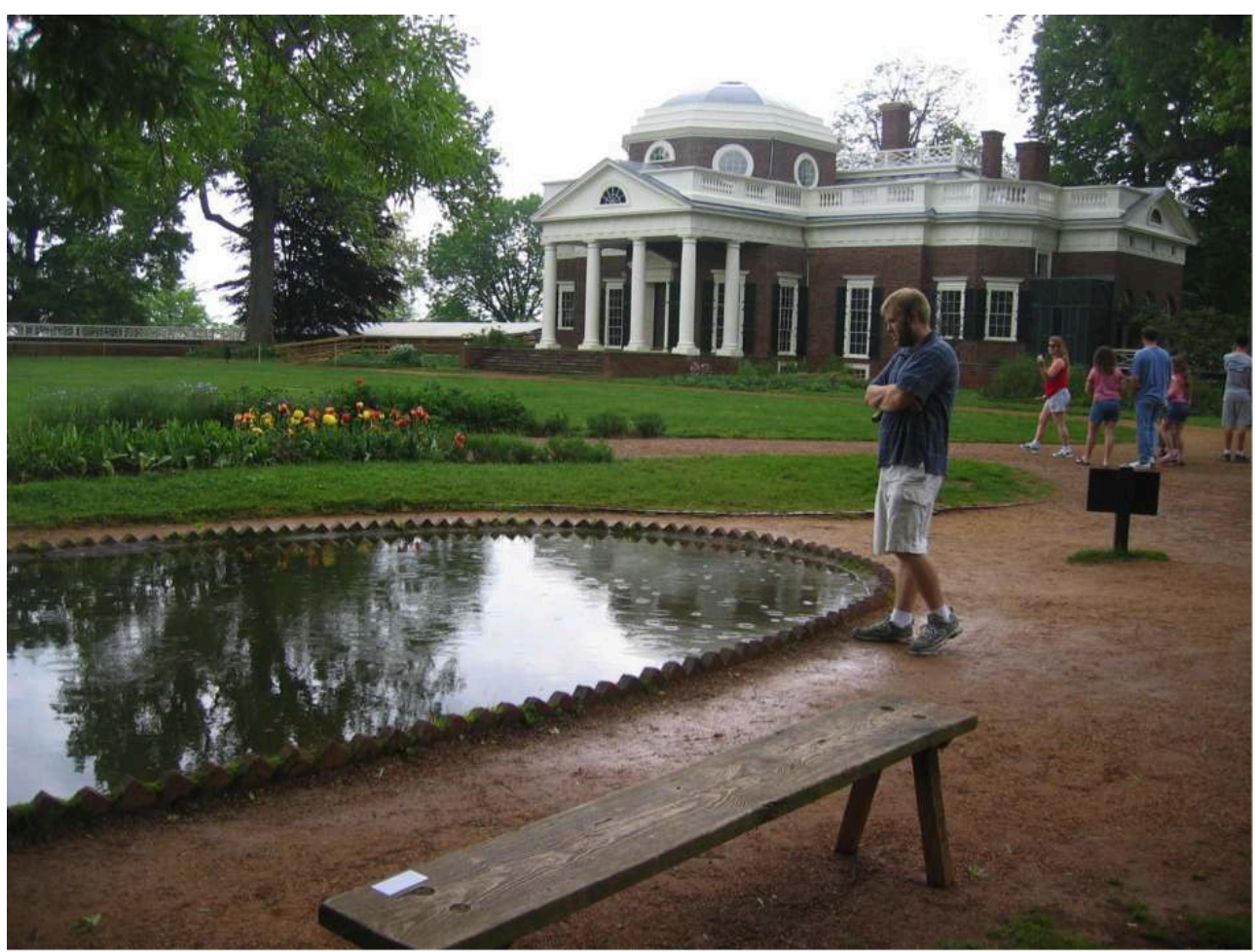

Implementation sticker on wooden bench at Monticello, Thomas Jefferson's home in Charlottesville Virginia.

1. As implied above, Implementation is an iterative work that took multiple forms-it has appeared as PDFs of sticker sheets, as individual stickers situated in the world, in online databases of photographic documentation, in gallery installations, in performative readings, and as a photo book. In every case, although elements of the text are consistent, the project changes as it is manifested in these different contexts. I think this is something it has in common with many examples of electronic literature, which are perhaps best thought of not as individual "works" per se, but as projects with multiple manifestations. 
Illustration \#9

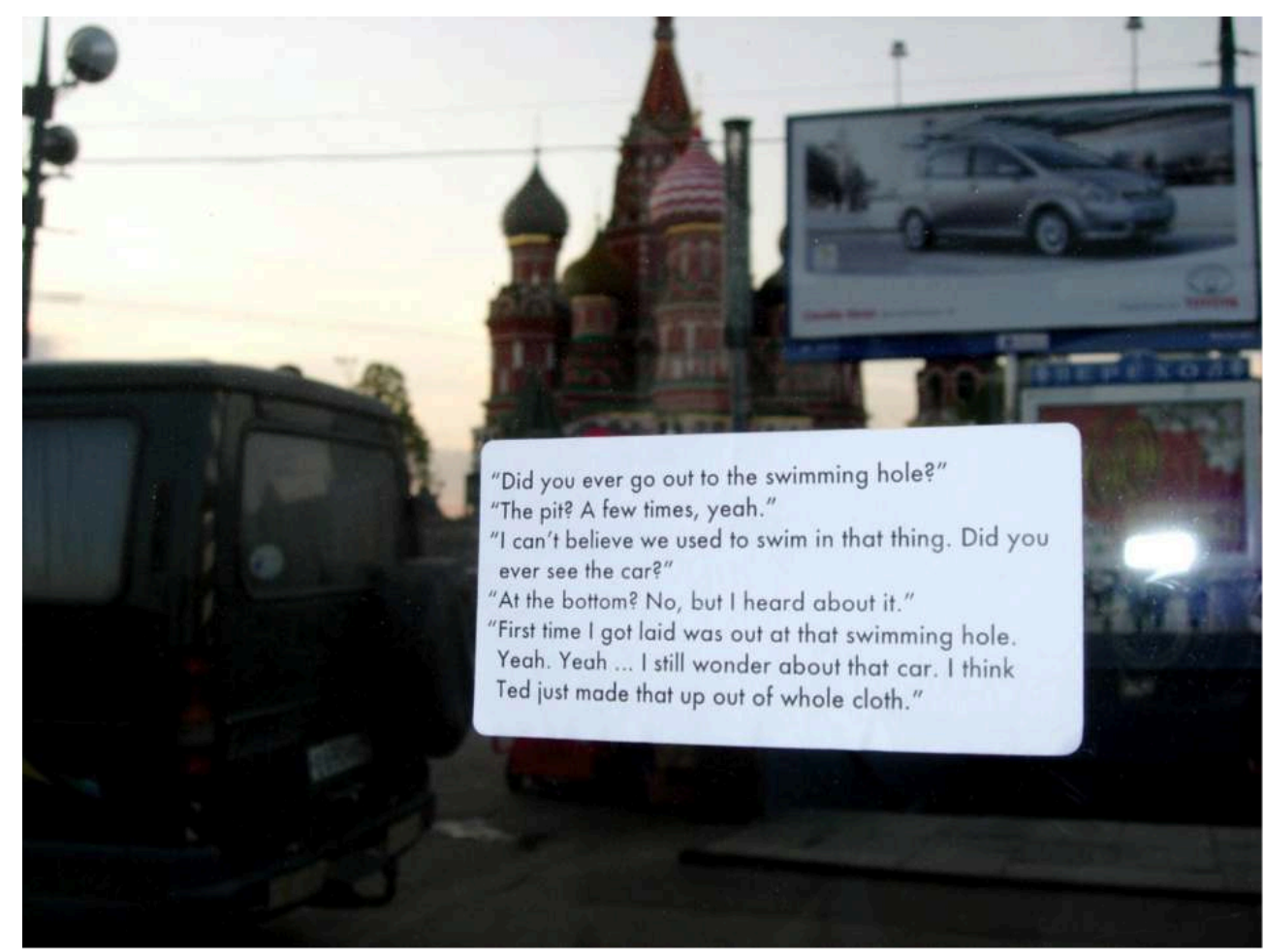

Implementation sticker on a bus stop in Red Square, Moscow.

\section{Katastrofetrilogien / The Catastrophe Trilogy: Disaster and Memory}

16 Since 2010, I have been collaborating with the filmmaker Roderick Coover on narrative films, combinatory films, and an immersive virtual reality project. The majority of these projects in some way address problems faced within contemporary society, most predominantly the increasing toll that climate change is taking on the world that we inhabit and have transformed in the Anthropocene.

While I have collaborated with other writers and artists throughout my career, this collaboration has opened up new avenues of research and creation for me, as Coover and I come from such different creative backgrounds, as a fiction writer and filmmaker. While we work together very closely on many aspects of the project, we also maintain a clear separation of roles: I do words (and sometimes programming) and Rod does images. This separation has been useful for us as we conceive of creative process as a dialectic between language and image that has a great deal in common with surrealist methods of collaboration and with a database logic. Even in the films that have a fixed structure, we don't necessarily start with a fixed script and then shoot from it, but often begin with a set of images and/or a set of texts. We exchange texts and images in an iterative process, developing both the images and the eventual script in tandem, with elements building in response to each other and layering. Then we work with voice actors. In most of the films we have made so far, humans are very much present in the film, but generally as voices rather than as embodied actors seen on screen. This is partly to do with the practical considerations of making films on little or no budget, 
but it is also a consequential aesthetic choice. The images in the films, of panoramic landscapes, of shipyards and abandoned buildings and industrial sites, of shorelines and waters, are coupled with voices in ways I think bring us closer to the consciousness of speakers even as we are distanced from their bodies.

Illustration \#10

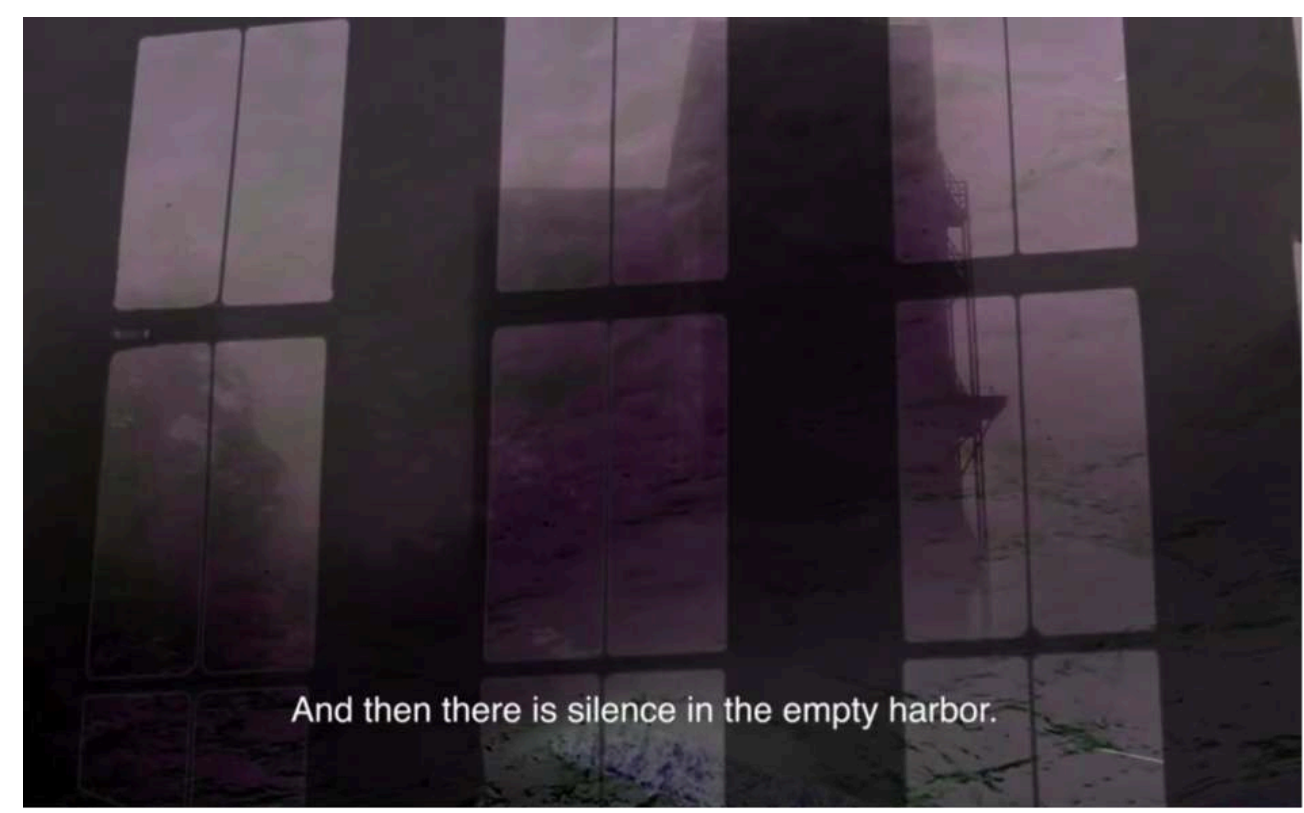

IMAgE FROM RATS AND CATS / KATTER Og ROTTER.

18 It is somewhat obvious but nevertheless worth noting that the voice actors interpret the texts that we provide them, and those interpretations have radically transformative effects (positive and negative) on the resulting narrative, as they embody the text. The human voice is an incredibly powerful instrument, and the same words can mean quite different things depending on how they are vocalized. I am always surprised by the way that the way that the movement from the page through the minds and vocal cords of the actors translates my writing into something other than what it was on the page. The iterative process of combinatory exchange continues through this part of the process. We have often recorded multiple takes of these scripts with different actors, or changed the script after the recordings have been produced. The speech act becomes part of the writing process.

The first three films that Coover and I made between 2010-2012 are particularly concerned with the reception of catastrophes and disasters, in how we as a species and in particular as a hypermediated species, variously pay attention to, absorb, and then fail to remember or mark patterns of catastrophe, or to change our behaviors or economies as a result of them. So the three films center on historical disasters that have managed to be forgotten and yet mirror contemporary concerns. They are about memory, cultural memory. A secondary concern of this series of films is interlinguistic communication and miscommunication across cultures. All of the films are in some way bilingual, including Norwegian and English. The three films in the trilogy each take a historical disaster from the history of Norway and re-situate it, using the historical event as a lens through which to view and consider contemporary circumstances: The Last Volcano / Det siste utbruddet focuses on an 18th-century volcanic eruption in Iceland, 
which subsequently had serious impacts and Norway and Europe; Cats and Rats / Rotter og katter centers on memories of the black death, filtered through a blind date between an American epidemiologist and a Norwegian woman conducted on Skype; Norwegian Tsunami / Norsk flodbølge deals with a devastating prehistoric tidal wave which carved away parts of the Norwegian and Scottish coastline and in the process created the English channel. That film is set within a conversation between a Norwegian chef and a Scottish engineer that takes place on an oil platform in the North Sea.

Illustration \#11

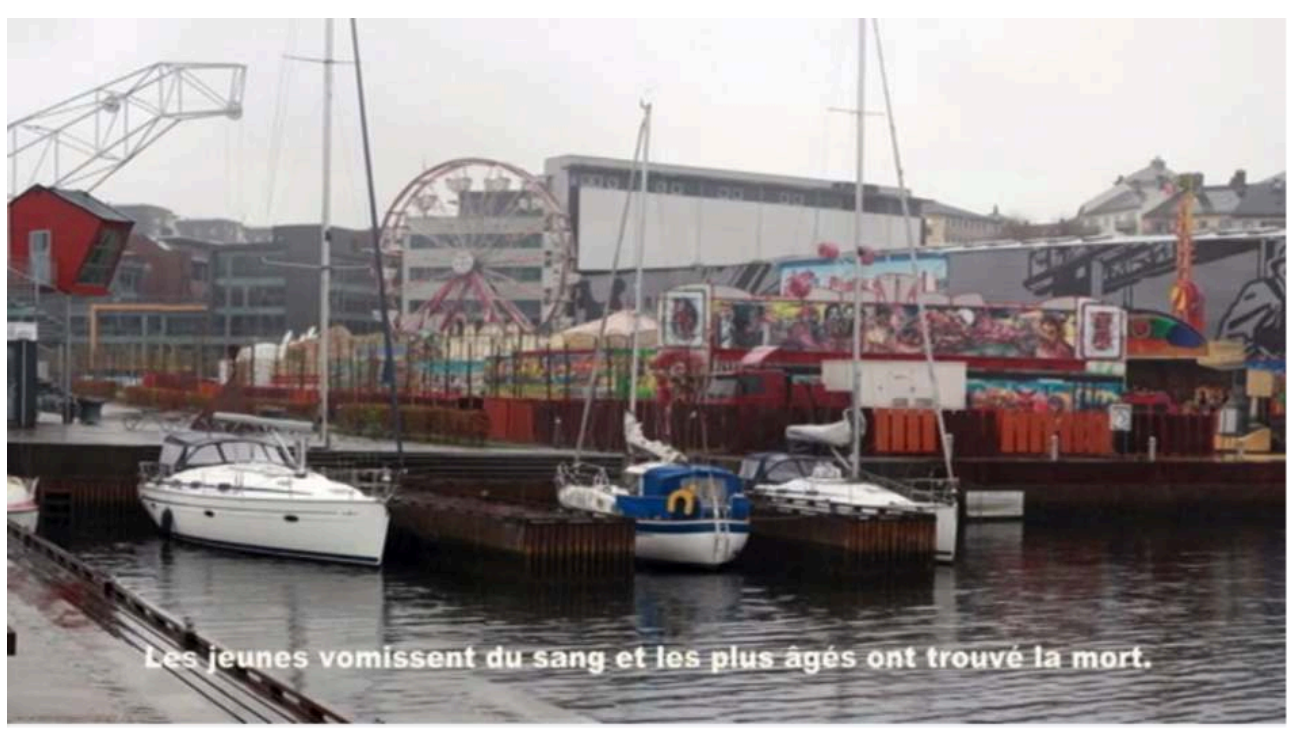

IMAgE FROM THE LAST VOLCANO (LE DERNIER VOLCAN).

20 I'll show The Last Volcano, the first film that Rod and I made together, in a version with French subtitles, Le Dernier Volcan. The Paris 8 translation and PTN students I am working with now are developing French versions of other scripts from this collaboration, so I anticipate that soon we will have subtitled, and perhaps even voicedubbed, versions of several of these projects in the near future.

\section{Three Rails Live: Dissolution and Juxtaposition}

The next project Three Rails Live (see excerpt online) is a work that is explicitly combinatory in structure. Roderick Coover, Nick Montfort and I developed this project together, working between Bergen, Philadelphia, and Boston, and finished the first draft while travelling on a train from Philadelphia to Providence. In this case, the process was very much like constructing an exquisite corpse. Roderick Coover first emailed Nick Montfort and I some images. Working independently, we each had different reactions to them. As I looked through the images, I began to code them into themes, and to think of them as writing prompts that would become the building blocks of a narrative. Nick Montfort, taking another approach, responded to them in an aphoristic way, and wrote in a form that Harry Mathews coined perverbs-yoking together two proverbs and creating a new, often comical, meanings from them. As in other projects, the process included several cycles of exchange, with Roderick Coover adding new images and video to the database in response to the texts we were giving him, and we in turn writing new texts in response to those images. Another fairly odd 
circumstance played into my writing process. During this period I had nearly lost a finger after a colleague had accidentally slammed my hand in a car door, and my hand was in bandages. So I wrote the narrative texts using a speech-to-text dictation program. This is the first time I tried writing by first speaking. I then (with my remaining good hand) edited the texts that I had spoken, and recorded them as voiceover tracks. So the narratives started as vocalizations, and then became texts, and then became vocalizations again. The story that emerged from my response to the images in the fragmented narrative is a story of dissolution, both of a particular human life and of the global environment.

Illustration \#12

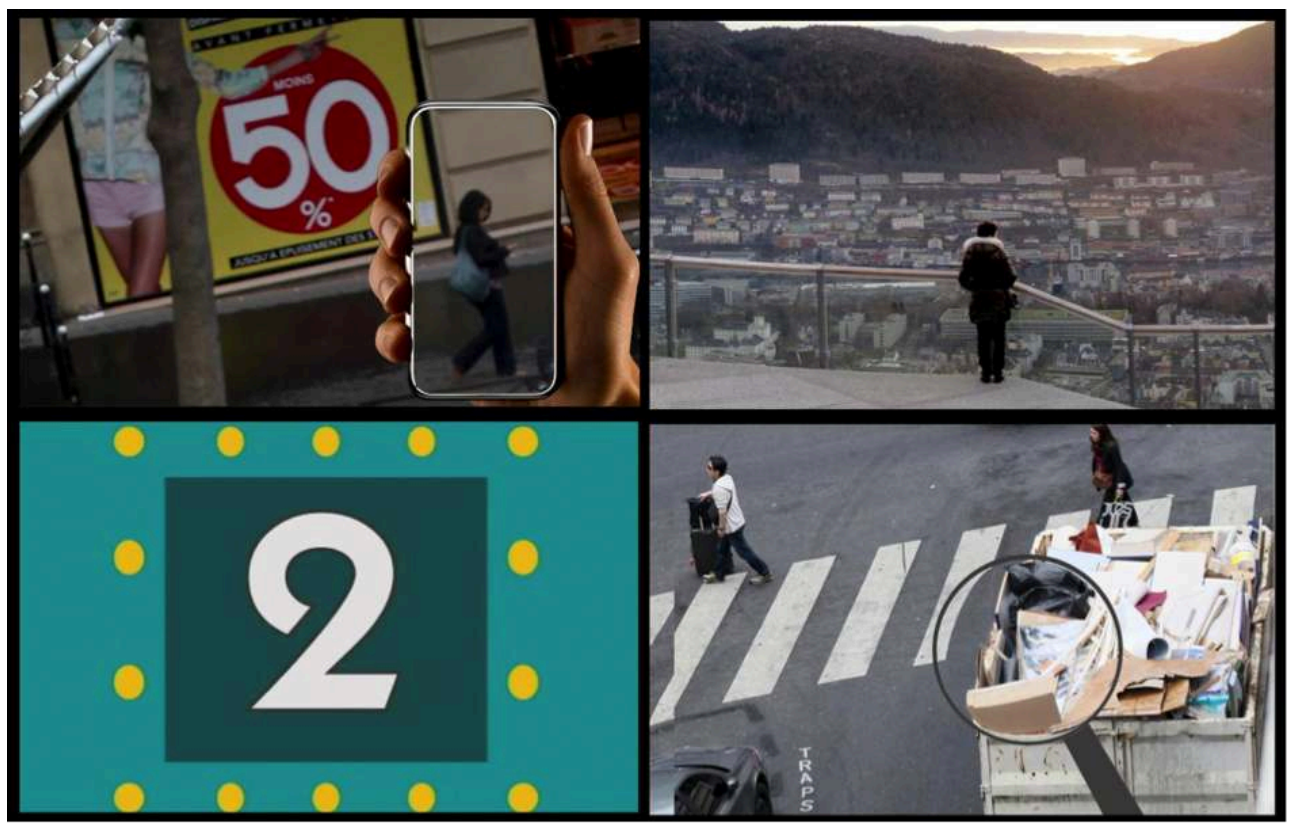

Collage of images from Three Rails Live.

When we looked at the texts and images we had independently produced and tried to consider how they might fit together, we concluded that Montfort's perverbs might serve as "morals" to the story. Montfort also produced a title generator. So on each cycle, the program generates a story title, selects two spoken narratives from the database and matches them two video segments (one with matted imagery, and one not matted), and provides one moral to the story. The narratives are joined to the video in a process that is also aleatory. The juxtapositions between the image and the text, and the morals to the stories, are thus different every time the program runs. Though the juxtapositions are randomized, the texts were all written in response to images in the set, so there is a kind of thematic cohesion even though the procedures involve randomization.

\section{Toxi•City: After the Deluge}

Toxi•City (see 13 minute online video excerpt) is a hybrid-narrative film that follows six fictional characters who live in a near-future landscape along the eastern seaboard of the USA, in the area of the Delaware River Estuary, which was one of the first 
industrialized port districts in North America and is today home to five of its largest oil refineries. The project asks what how conditions of life would change if repeated storm surges and tides flooded the densely populated lands with toxins from the hundreds of sea-level petrochemical industry sites and post-industrial brownfields.

Illustration \#13

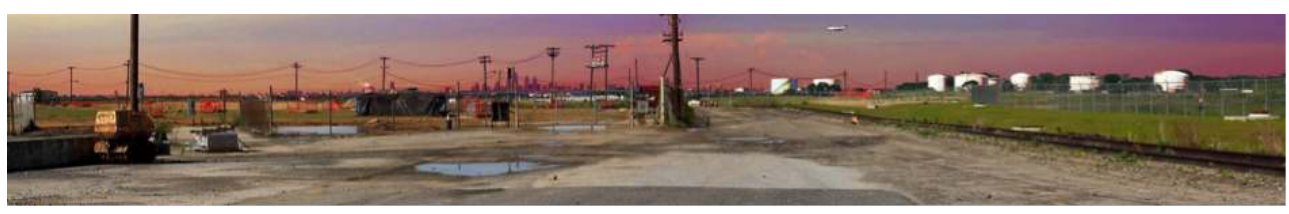

Image from Toxi·City.

Toxi•City was originally made for a commission for the Sensing Change exhibition at the Chemical Heritage Foundation Museum of Philadelphia in 2013, which presented artworks communicating scientific knowledge about climate change. In October 2012, just as we had begun work on developing script ideas for the commission, Hurricane Sandy hit the east coast of the USA. I remember that I was attending a conference in Edinburgh, Scotland. I opened my hotel room door and saw the front page of the newspaper, printed a few days after the storm. President Obama was standing on the shore in front of a scene of devastation. The scene looked strangely familiar to me, and then I realized that Obama was standing on the Atlantic shore of Brigantine, the boundary island where I used to live in New Jersey. The house where I used to live was somewhere in that flooded landscape of ruined homes. Since the reality of Sandy related so directly to the potential near-future we intended to visualize in the film, we decided that the film should integrate a non-fiction layer that referenced this real storm and its direct consequences. The fictions of Toxi.City are thus interspersed with nonfictional accounts of deaths that occurred during recent storms in the area, including some of many who died in New Jersey and New York as a result of Hurricane Sandy.

Like Three Rails Live, Toxi•City is a combinatory film. As we watch the film, some stories seem to resolve, while others unravel. Just as with the conditions of ocean tides and tidal shores, the stories cycle and change without clear beginning or end. Individuals grasp for meaning from fleeting conditions of a world in flux. As the characters paths intersect, story threads come together. These offer moments of resolution, contact and visions of the future, before the narratives are broken apart and a fresh cycle begins anew. It is a hybrid film in that it combines narrative elements with documentary imagery and elegiac nonfictional anecdotes, tying imagined futures to the realities of our contemporary condition. The inclusion of these short fragments of real lives lost in contemporary storms grounds the speculative elements of the climate change narrative. The fact that there are many of these stories of personal demise, and that viewers of the film never encounter the same combination of these fragments twice, reiterates the immense scale of loss that such disasters involve. 
Illustration \#14

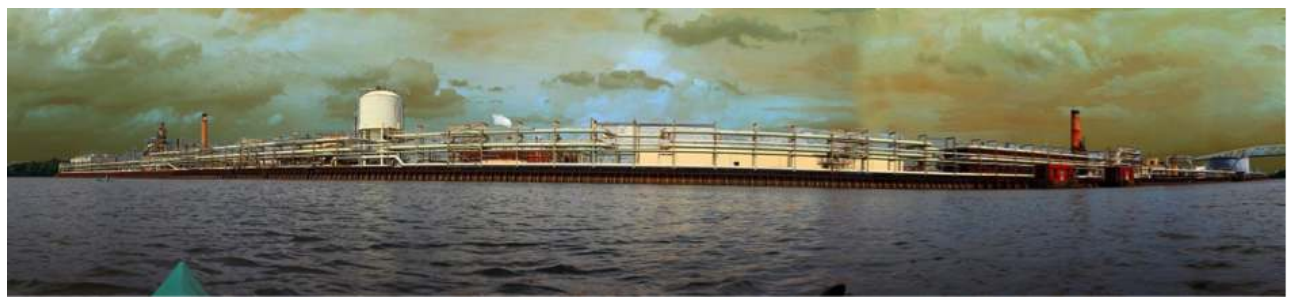

Image from Toxi•City.

During 2014, we have expanded the project to a feature-length version. We are still in the process of adding new clips to the database that expand the context of the narrative. Toxi-City is adapted differently for different screening situations. When it is run in a museum context as an installation, it will run for about 30 minutes before regenerating a new version. In cinematic settings, it can be shown as a feature length film of about 50 minutes. When the project is complete, there will be about 120 minutes of content in the database, so any given run will include only about half of the potential narrative. There is some set narrative structure within the randomization of elements, in that there are some fixed beginnings and some fixed endings (eventually three sets of each). The middle segments and the elegiac stories delivered by the application vary on each run.

\section{Hearts and Minds: The Interrogations Project: Addressing a Travesty in a CAVE}

The last project I will briefly present here is Hearts and Minds: The Interrogations Project. This project makes use of the CAVE environment for a multisensory artwork that addresses a complex contemporary problem: as American soldiers are returning from wars in Iraq and Afghanistan, it is becoming increasingly clear that some of them participated in interrogation practices and acts of abusive violence with detainees for which they were not properly trained or psychologically prepared. This has in turn left many soldiers dealing with Post-Traumatic Stress Disorder on their return home, and left many unresolved questions about the moral calculus of using torture as an interrogation strategy in American military operations. 


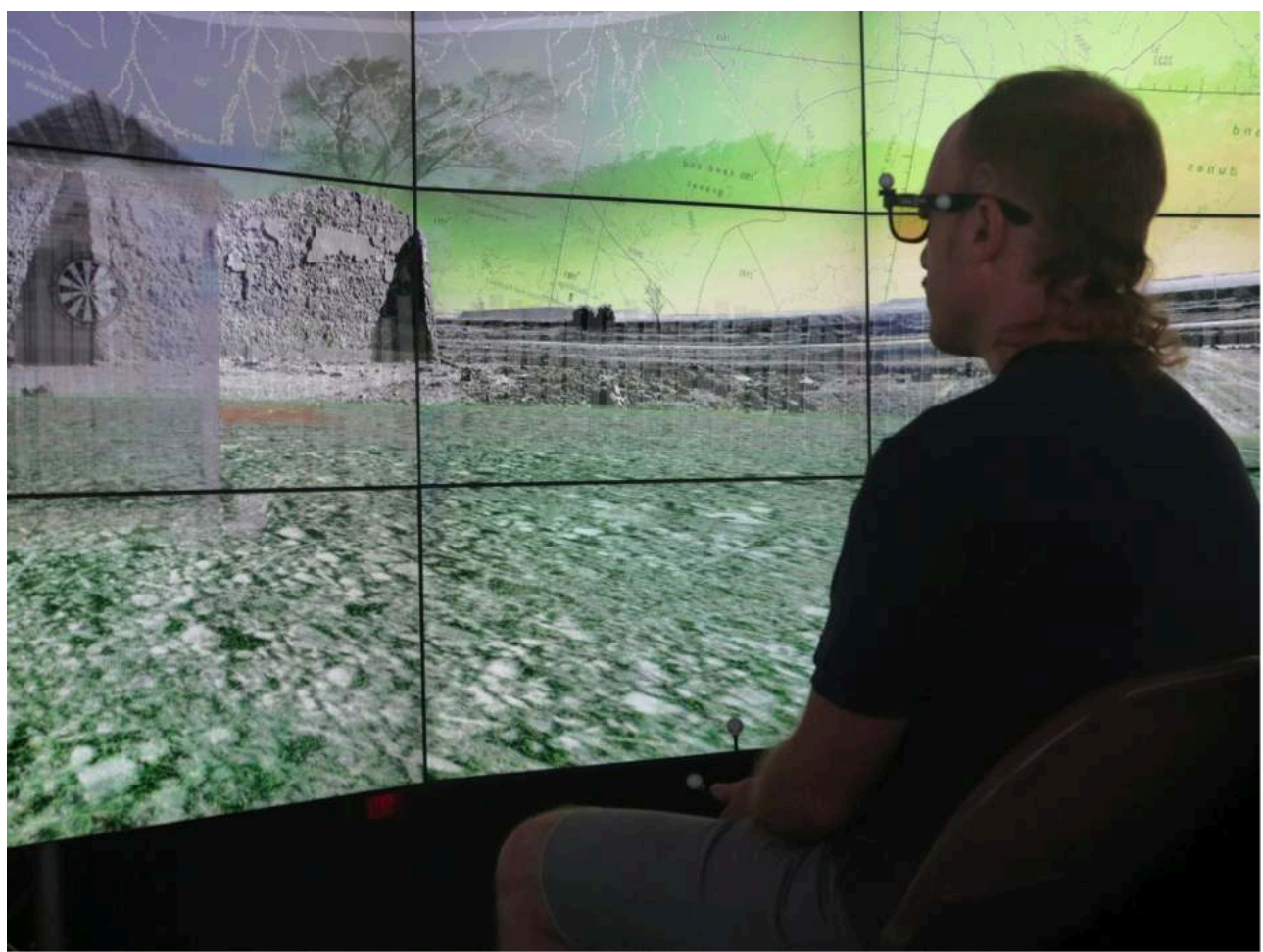

Performance artist Mark Jeffery interacting with Hearts and Minds during a rehearsal for the June 2014 performance of the work in the CAVE2 ${ }^{T M}$ immersive virtual reality environment at the EVL, University of Illinois Chicago.

This project is based on scientific research that addresses a significant problem-the cultural inheritance bequeathed us by the tactics employed during the war in Iraq. Based on interviews of soldiers who participated in or observed acts of torture rather than purely statistical data, this problem was then further narrativized through visualization techniques. The immersive 3D environment of the CAVE is here intended to provide an affective environment that produces a space for interpretation. The visualization environment serves as a dispositif for enacting individual and cultural memory of an institutionalized atrocity.

The project was developed through a unique collaboration between artists, scientists, and researchers from four universities. The project is based on interviews of American soldiers conducted by political scientist, Dr. John Tsukayama. I was the lead writer on the project, adapting a script from material gathered in 17 interviews that Tsukayma conducted with American soldiers who had been directly involved with interrogations of prisoners in Iraq, many of which crossed the line into the zone of torture. The development team included filmmaker Dr. Roderick Coover, artist and visualization researcher Daria Tsoupikova, computer scientist Arthur Nishimoto, and sound designer Mark Partridge. Dr. Jeffrey Murer, Lecturer on collective violence at St. Andrews University, Scotland also contributed as a consultant on the project. 


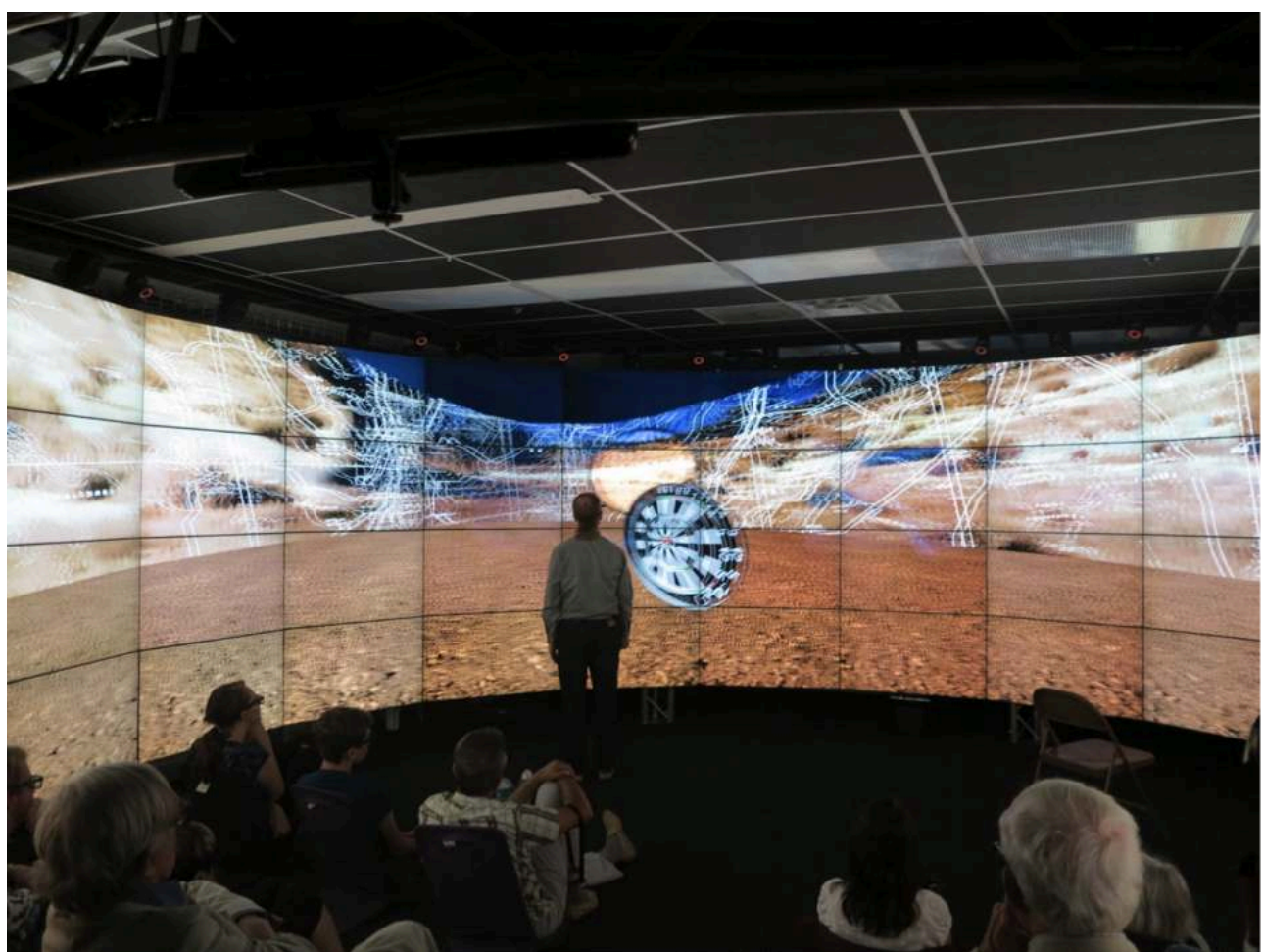

Performance artist Mark Jeffery interacting with Hearts and Minds during a July 2014 performance of the work in the CAVE2 ${ }^{\mathrm{TM}}$. An object, the dartboard, has just been triggered, transporting the viewers to a surreal subconscious landscape where a story of prisoner abuse is recounted.

The project presents the audience with a narrative environment that begins in a reflective temple space with four doors opening to ordinary American domestic spaces: a boy's bedroom, a family room, a suburban backyard, a kitchen. The performer navigates the environment using a wand, a 3D mouse, to interact with and control a VR experience in the CAVE2 $2^{\mathrm{m}}$. The virtual scene is continuously updated according to the orientation and position of the head, as measured with head and arm trackers, and the 3D view of the scenes is focalized on this perspective. Moving through and exploring each these rooms inside the virtual scene creates a sense of being immersed in the virtual environment. Using a wand with buttons, the navigator triggers individual objects, such as a toy truck, a Boy Scout poster, or a pair of wire cutters. When each object is activated, the walls of the domestic space fall away and a surreal desert landscape is revealed in 2D surrounding panorama, and one of the four voice-over actors is heard recounting particular acts and memory related metaphorically to the object selected. The objects also function very much like hyperlinks in moving us from one narrative element to another. Viewers travel through the domestic spaces and surreal interior landscapes of soldiers who have come home transformed by these experiences, triggering their testimonies by interacting with objects laden with loss.

31 This version was ported in Unity from the original CAVE performance version to a stand-alone version for exhibition and performance contexts outside of the CAVE. A version for iPad and Android tablets is also in the works. While these versions do not have the same effect of total immersion that the CAVE provides, they will make the project accessible to a wider audience. A brief online documentation video is available for an impression of the work in its original context. 


\section{Conclusion: The Ends of Electronic Literature}

I think it is important to resist the notion that the primary value in the field of electronic literature is or should be the novelty of digital forms; there are problems with the innovative aesthetic use of the device for the sake of innovation alone. If the modernists implored us to "Make it new" I sometimes feel that in electronic literature we see the invention of new genres at the speed of technological innovation: too many new forms, too fast, in a kind of Futurist blur of acceleration. There is a real tension between continuous innovation and meaningful literary expression. If every artist produces a new form, if every work manifests a new genre, electronic literature might never develop the richness of shared contexts and discursive context, the dialectics of tradition, transition, and originality that characterize print literary traditions. So I might stand among the garde derrière rather than the avant garde of this field, and argue that one of the imperatives of electronic literature should be to "Make it not new." Play and innovate, by all means, but try to work with forms and genres until they become available at-hand as creative environments and pliable as forms of expression, potentially as a means for reflecting and commenting critically on contemporary social and political reality. Explore by all means, but also map and inhabit one territory before rushing on to the next. Use new forms not merely to celebrate their technical affordances, but because they enable the work to mean something in the world in a way that it otherwise could not. I would never argue that technical innovation is unimportant in experimental narrative in digital media, nor that literature should in every case address the societal challenges and controversies of contemporary life. But this kind of work offers us the potential to do much more than play language games in digital media. Multimedia, computational, networked environments offer us powerful new ways to communicate and to wrestle with the challenges we face as human beings in the 21st century. One of the most important functions of print novels has been to provide us with a way to process and frame our culture as we have lived within it, as we collectively construct our future memories of the past. Works of digital narrative offer the same potential in the networked computational reality of the present. Electronic literature's specificity as an art form produced within the dominant communication environment of our age, within the very same apparatus that seeks increasingly to monitor and discipline, to afford and constrain our shared reality, nearly demands that we engage critically with that apparatus and produce artworks within the digital context that are not simply about their own form as digital artifacts, but instead provide us with new ways of reflecting on our situation within and our relations to a troubled and challenged world. 


\section{BIBLIOGRAPHY}

Carpenter, J.R. Gorge. 2011. Last update unknown. Checked on Jan. 31, 2016.

<http://luckysoap.com/generations/gorge.html>

Coover, Roderick and Scott Rettberg. Cats and Rats / Rotter og katter. 2011. Last update unknown.

Checked on Jan. 31, 2016.

<https://vimeo.com/50355051>

Coover, Roderick and Scott Rettberg. Norwegian Tsunami / Norsk flodbølge. 2012.

Coover, Roderick and Scott Rettberg. The Last Volcano / Det siste utbruddet. 2010. Last update unknown. Checked on Jan. 31, 2016.

$<$ https://vimeo.com/57377350> (English subtitles). Le Dernier Volcan (French subtitles)

<https://vimeo.com/113107102>

Coover, Roderick, Nick Montfort, and Scott Rettberg. Three Rails Live. 2012. Sample online:

$<$ https://vimeo.com/73507741>

Coover, Roderick, Arthur Nishimoto, Scott Rettberg and Daria Tsoupikova. Hearts and Minds: The Interrogations Project. 2014. Application for performance in the CAVE2 ${ }^{\mathrm{TM}}$ immersive virtual reality environment in the EVL at University of Illinois Chicago, and as a stand-alone Unity application. Last update unknown. Checked on Jan. 31, 2016. Short documentation video excerpt: <https://vimeo.com/107178964>

Coover, Roderick, Arthur Nishimoto, Scott Rettberg and Daria Tsoupikova. "Hearts and Minds: The Interrogations Project." Short paper. IEEE 2014 VIS Arts Proceedings. Last update unknown. Checked on Jan. 31, 2016.

<http://visap.uic.edu/2014/papers/16_Coover_Hearts_VISAP2014.pdf>

Memmott, Talan. “Toy Garbage.” 2010. Last update unknown. Checked on Jan. 31, 2016.

$<$ http://talanmemmott.net/toy/>

Montfort, Nick and Scott Rettberg. Implementation, a novel (project site). 2004. Last update unknown. Checked on Jan. 31, 2016.

<http://nickm.com/montfort_rettberg/implementation/>

Montfort, Nick and Scott Rettberg. Implementation, a novel (Coffee table photo book, 270 pages). 2012. Last update unknown. Checked on Jan. 31, 2016.

<http://www.blurb.com/b/3442475-implementation>

Montfort, Nick and Scott Rettberg. Implementation (Flickr photo archive). 2010. Last update unknown. Checked on Jan. 31, 2016.

$<$ https://www.flickr.com/photos/implementation>

Montfort, Nick. Taroko Gorge. 2009. Last update unknown. Checked on Jan. 31, 2016.

<http://nickm.com/poems/taroko_gorge.html>

Funkhouser, Chris. "Cannibalistic Tendencies in Digital Poetry: Recent Observations and Personal Practice.” 2009. Harriet (Poetry Foundation blog). Last update unknown. Checked on Jan. 31, 2016.

<http://www.poetryfoundation.org/harriet/wp-content/uploads/2009/12/bergen2nx1.doc>

Rettberg, Scott. “Tokyo Garage.” 2009. Last update unknown. Checked on Jan. 31, 2016.

$<$ http://retts.net/tokyogarage.html> 
Rettberg, Scott. "Human Computation in Electronic Literature" in Handbook of Human Computation. Pietro Michelucci, ed. New York: Springer, 2013. Last update unknown. Checked on Jan. 31, 2016.

<http://elmcip.net/critical-writing/human-computation-electronic-literature>

Sample, Mark. “Takei, George.” 2011. Last update unknown. Checked on Jan. 31, 2016.

<http://samplereality.com/elit/takeigeorge.html>

Snodgrass, Eric. "Yoko Engorged. 2011. Last update unknown. Checked on Jan. 31, 2016.

<https://5b7705e49483ebcda62f8e746f72b423a3b47a11.googledrive.com/host/oB-

_xkDymIRrCODBxaFFobnRaUlE/index.html>

Stiegler, Bernard. "Memory" in Critical Terms for Media Studies. W. J. T. Mitchell, Mark B. N. Hansen, eds. Chicago: University of Chicago Press, 2010.

\section{NOTES}

1. This article is a revised version of a "hybrid conference" given at the University of Paris 8 on Dec. 8, 2014. A slightly different version of this article has also been published in Hyperrhiz\#15, summer 2015: http://hyperrhiz.io/hyperrhiz12/mapping-e-lit/1-rettberg-situatingchange.htmlub. I would like to thank the Labex Arts-H2H and Paris 8 University for hosting me here as an international chair, and particularly Alexandra Saemmer, Arnaud Regnauld, and Philippe Bootz for helping to arrange my stay and for being such welcoming hosts. The hybrid conference was only one aspect of a productive and enjoyable two-month stay in Paris that has included my participation in four different conferences this November and weekly meetings with Master's students participating in a translation and remediation workshop. These students were working on translations into French and other languages and remediations of several of the projects I will present here. I enjoyed working with these bright and energetic LISH, MC2L, and PTN graduate students immensely, and I am grateful for the work that they are doing.

2. See Rettberg "Human Computation in Electronic Literature" for a detailed discussion of human computation and how it is manifested in some works of electronic literature.

3. Nick Montfort is someone who I would describe as this sort of activist. His "Facepalm at the End of the Mind" is a high-quality rant against Facebook and an elegy for the Web that very nearly made me stop using the social network. Though it did not quite work. I'm still on Facebook.

\section{ABSTRACTS}

This article is not intended as a traditional paper but rather it focuses on the presentation of some creative works I have produced in collaboration with other artists. In doing so I also intend like to consider how three aspects of what I do inter-relate:

1. work with combinatory aesthetics in the production of artworks-primarily literary, primarily narrative, made and often meant to be read within computational contexts;

2. collaborate with other artists, including other writers, programmers, visual artists and filmmakers, actors, and other sorts of hybrid practitioners: 
3. reflect political realities in these artworks and through digital narrative, to take discursive positions on real world issues and make them available for discussion, debate, and perhaps other kinds of direct engagement.

INDEX

Subjects: Digital arts

Keywords: combinatory aesthetics, digital literature, collaborative creative work, aesthetic politics

\section{AUTHOR}

\section{SCOTT RETTBERG}

Professor of Digital Culture

University of Bergen, Norway

Scott.Rettberg@uib.no 